\section{ELECTIVES IN THE DEVELOPING WORLD}

Choosing to do an elective in a developing country can be a gamble. Everyone has heard stories of unsuspecting students being deposited in a remote hospital and told that actually they are the doctor, and here are the hordes of patients they must look after for the next eight weeks. As if this isn't enough, the students often find themselves suffering severe culture shock, working in a health care service that bears no resemblance to the one they are accustomed to and encountering patients who frequently present with either unfamiliar diseases or unfamiliar presentations of familiar diseases.

Some would argue that this is an exciting and worthwhile experience from which the adventurous student can learn vast amounts. However, others may find it a lonely and stressful two months in which there is a lot of potential to blunder into problems through lack of understanding of local culture and health care practices. Worse still, for many students the prospect of working in a developing country is too daunting to even be considered an option.

The purpose of this article is to remove some of the fear from doing an elective in the developing world. Examples of the author's own experiences in Tanzania are used, and a few simple guidelines are provided which students can follow to ensure that they are fully prepared; enabling them to get the most out of their elective, and also give the best back. Finally, the concept of an "International Health Elective" as a model for successful electives in the developing world is discussed.

\section{How to prepare for your elective}

Decide where you want to go!

Obvious, but it is important that you make the right decision. A good resource to help you make this decision is other students who have completed their elective. You can usually contact such students through your medical school. Useful information can frequently be found in student medical journals, many of which carry students' elective reports from various countries(1). There are also books available for medics considering working abroad(2), and websites that cover international health issues(3). If concerns about safety may influence your decision, contact the foreign office in your country for some advice(4).

\section{Red Tape and Practicalities}

It is important to get the practicalities out of the way once you have chosen a destination and arranged your dates of travel. It is best to do this at least 3-6 months before you travel, as vaccination schedules may require a few months between boosters. Most of this information is available in good guide books (see Resources section at the end), but some key points relevant to medical electives are set out below.

Your health when abroad is extremely important. Make sure that you visit a travel clinic (either within your University or with your own doctor's practice) to obtain advice about necessary immunisations, appropriate anti-malarial prophylaxis and general health and safety issues relevant to your chosen destination. It is also worthwhile obtaining a regime of HIV postexposure prophylaxis drugs if the country you are visiting has a high prevalence of HIV; your University may be able to arrange this for you. Should you become unwell, it is useful to have a list of generic drug names so that you can easily request the medications you need. Some people even carry a kit with a few basic medications (analgesics, anti-diarrheals, re-hydration salts, antibiotics such as ciprofloxacin and metronidazole, and anti-emetics). However, this is not a substitute for medical advice if you are unfortunate enough to become ill while on your elective. Importantly, you must ensure that you have good health insurance for your elective - it is reassuring to know that your insurers will pay to fly you to hospital should you be struck down by a case of cerebral malaria in the middle of the African countryside. Additionally, you must ensure that you have insurance that covers you as a health care provider in your chosen elective destination. Check with the medical insurance groups in your home country as many of them also cover elective students overseas.

Finally, financing the elective. Depending on your destination, the costs of flights and living expenses may not be excessive, but can nevertheless be significant. It is worthwhile to look for grants and bursaries that will offset at least some of the costs of your trip. Often grants are given if you are intending to carry out research whilst on your elective (for example, those from the Wellcome trust(4)). Most grants are specific to the types of research or country being visited. Your medical school will be able to tell you which grants and bursaries are available to you and how to apply for them.

\section{Learn about your destination country}

This greatly enriches the elective experience. Developing countries are by their nature very different from countries in the west; it helps to understand these differences before you go. Find out about the economic 
status, political climate and culture of the country you are going to visit. Try and study its history, how it became part of the "developing world" and what this label means for it now. Doing this will help you understand the behaviour, attitudes and lifestyle of the people around you, making you less prone to culture shock. If you have time, read about the global players that influence the politics (and thus health care provision) in the country, such as the World Bank, International Monetary Fund and World Health Organisation. Some useful references are listed in the resources section below.

It also pays to "know the lingo"; essential for communicating with local people within the hospital and the community. Make sure you can speak at least one of the national languages. Whilst you can often get by with English in many developing countries, it helps if you have taken a few classes in local languages before you arrive-particularly when it comes to getting histories from your patients.

\section{Learn about the local healthcare system}

The government health care system in many developing countries is based on a western model that has evolved according to the changing political climate. Alongside this many countries have a private health care service and traditional healers. Before you go, find out about the health care system that exists in your destination, what services are available (public/private/traditional), how these are financed, who uses them and how effective they are at meeting the health needs of the population. This will help you understand the circumstances under which the medical staff must work; having some knowledge of how desperately under-financed the Tanzanian health care system has certainly helped us to appreciate the stress and attitudes of the staff we were working alongside.

Find out about the general health of the population in the country you are visiting. Which diseases are common and how do they manifest themselves? What is the life expectancy? What is the HIV prevalence rate? Statistics can be found on some of the websites listed at the end of this article.

\section{Contact the hospital}

Make contact with the appropriate people at your chosen destination and attempt to organise a programme of study before you go. Arrange to spend time learning alongside students wherever possible. Ensure that your experience will be in all areas of the health care system (public/private, rural/urban, primary/tertiary) as this will give you a fuller understanding of the health care situation. Find out which medical staff are in the hospital and try to arrange a senior doctor to be your supervisor when you are in the country, with whom you should agree on objectives you want to achieve during your elective. Your supervisor should be able to facilitate if things are not going according to the programme.

In Tanzania it was possible to arrange a comprehensive programme of study before we left the UK. We were allocated to specific medical firms, and a week was set-aside for us to accompany a group of students on their community placement to a rural hospital. This thorough preparation meant that we were able to see how health care was provided at all levels during our two-month stay. The rural placement allowed us to see for ourselves the difficulties faced by the majority of Tanzanians: an invaluable and humbling experience.

Make contacts before you go!

As mentioned, one of the most important resources you can use when preparing for your elective is information from medical students in the country you are planning to visit. You can do this using international student networks such as the International Federation of Medical Students' Associations (IFMSA). Students will let you know what to expect when you arrive in the country, tell you the sorts of things you will need to bring, and of course it is advantageous to build up friendships before you arrive.

\section{When you arrive}

Students are an even greater resource once you are on your elective. They know a lot about the conditions you will see, and also the predicament of doctors within that country. They can provide the support, assistance and understanding of issues (both inside and outside the hospital) needed to get the most out of the elective experience. Spending time with them will help you understand important cultural differences between your home country and elective destination, such as time keeping, behaviour and dress code. While you may find some of these differences difficult to accept, it is necessary to respect, and avoid offending local people.

Working with other students on the wards and in clinics helps to overcome language and cultural barriers. In Tanzania, we frequently relied upon students to assist in translating histories. The students also have plenty to gain from you; the exchange of skills, knowledge and attitudes that occurs as you interact is of mutual benefit. We demonstrated how to examine a patient with suspected Parkinson's disease (a rare condition in Tanzania), and they taught us about malaria, HIV, tuberculosis and other diseases that they commonly encountered. Ultimately, it was the close friendships that we built up with the medical 
students in Tanzania that truly enhanced our elective experience.

\section{When you return home}

Keep in touch with your peers in the country you have visited. Friendships between students facilitate the future exchange of knowledge, ideas and understanding between the two countries. In an increasingly globalised world this sort of communication helps you to keep up to date with what is happening to health care on a global scene.

Final points on completing an international health elective

The International Health and Medical Education Centre (IHMEC) at University College London runs an international health elective programme. Students first complete four weeks of pre-elective tuition covering issues that affect health care provision in the developing world, preparing the ground for the elective. When abroad, they are tutored by local health care workers and faculty teachers at all levels of health care, in conjunction with the local students. Students benefit from being in close contact with their peers in the host country, and also feel reassured by the integrated program and support provided. This year is the third year that IHMEC has run international health electives and students have been placed in several different developing countries.

Not all medical schools have an international health centre within their university, but students across the globe are free to use IHMEC as a resource to assist them in preparing for their elective experience. The centre is currently in the process of designing a pre-elective pack for those who cannot do the full elective programme of tuition prior to travel and de-briefing on returning home. This covers issues of globalisation, poverty, donor aid, access to drugs and other topics that affect health care provision in the developing world. It also includes a list of useful reading material and advice (3).

\section{Conclusion}

It is important to be fully prepared for your elective, particularly if you are aiming to visit the developing world where lifestyle, customs and living conditions are likely to differ significantly from those that you are used to. Whether just by taking a little time to do some reading before you go or experiencing an "international health elective", you can enhance your experience, making your elective both educational, enjoyable and of benefit to both you and your hosts.

\section{Resources}

General information
1.International Health and Medical Education Centre: www.ihmec.ucl.ac.uk

2.CIA: www.cia.gov/cia/publications/factbook

3.UK Foreign and Commonwealth Office, for general information (and any travel warnings) about specific countries: www.fco.gov.uk

\section{Your health}

1. UK Department of Health travel advice: www.doh.gov.uk/traveladvice

2. London School of Hygiene and Tropical Medicine: www.lshtm.ac.uk

3. Centers for Disease Control and Prevention (information about HIV post-exposure prophylaxis: www.cdc.gov/travel

4. Jones N. The Rough Guide to Travel Health. Rough Guides, 2001

\section{Background reading}

1. The Rough Guide and Lonely Planet guidebooks, including the Lonely Planet website:

www.lonelyplanet.com Wilson, M. The Medics' Guide to Work and Electives Around the World (2nd Edition). Edward Arnold, London, 2003.

2 Jong EC, McMullen RM. Travel and Tropical Medicine. WB Saunders, 2002, Eddleston M, Pierini S. The Oxford Hnadbook of Tropical Medicine. Oxford University Press, 1999.

3. Bell DR, Beeching NJ, Gill GV. Lecture Notes on Tropical Medicine (5th edition). Blackwell Science UK, 2003.

\section{Health care in the developing world}

1. World Health Organisation: www.who.int

2. International Committee of the Red Cross: www.icrc. org

3. Médecins sans Frontiéres: www.msf.org

4. Centers for Disease Control and Prevention: www .cdc. gov

5. International AIDS Vaccines Initiative: www.iavi.org 6. Global Fund for AIDS, Tuberculosis and Malaria: www.globalfundatm.org

\section{Developing world economics}

1. United Nations Development Programme : www.undp.org

2. World Bank: www.worldbank.org

3. World Trade Organisation: www.wto.org

4. World Development Movement:

www.wdm.org.uk

5. Hunger notes (food security issues): www.worldhunger.org

6. MedAct (an NGO for health professionals): www.medact.org 
7. One World: www.oneworld.net

8. Unicef: www.unicef.org

9. The United Nations: www.un.org

10. Millenium Development Goals:

www.developmentgoals.org

\section{Electives in the developing world}

1. The Student BMJ website (www.studentbmj.co.uk) carries an elective report in all of it's issues, frequently from developing countries. Search the website for a report from any country you are particularly interested in. 2. Banatvala N, Doyal L. Knowing when to say "no" on the student elective. Students going on electives abroad need clinical guidelines. British Medical Journal. 1998 May 9;316(7142):1404-5
Getting in touch with students

1. International Federation of Medical Students Associations: www.ifmsa.org

\section{REFERENCES}

1. The Student British Medical Journal: www.studentbmj.co.uk 2. Wilson, M. The Medics' Guide to Work and Electives Around the World (2ndEdition). Edward Arnold, London, 2003.

3. International Health and Medical Education Centre: www.ihmec.ucl.ac.uk

4. The Wellcome Trust: www.wellcome.ac.uk

Dr. Shiner is currently working as a pre-registration medical house officer at the Royal Preston Hospital, Lancashire, UK. She is interested in pursuing a career in international public health policy. Dr Jaime Miranda is the International Health Electives Co-ordinator at University College London 